\title{
A Global Analysis of the Relationship Between Urbanization and Fatalities in Earthquake-Prone Areas
}

\author{
Chunyang $\mathrm{He}^{1,2} \cdot$ Qingxu Huang $^{1,2} \cdot$ Xuemei Bai $^{3} \cdot$ Derek T. Robinson ${ }^{4} \cdot$ \\ Peijun Shi ${ }^{1,5,6} \cdot$ Yinyin Dou ${ }^{7}$ Bo Zhao ${ }^{8}$ Jubo Yan' ${ }^{1,2 i a n g}$ Zhang ${ }^{1,5}$. \\ Fangjin $\mathrm{Xu}^{1,2} \cdot$ James Daniell $^{10}$
}

Accepted: 23 November 2021 / Published online: 21 December 2021

(C) The Author(s) 2021

\begin{abstract}
Urbanization can be a challenge and an opportunity for earthquake risk mitigation. However, little is known about the changes in exposure (for example, population and urban land) to earthquakes in the context of global urbanization, and their impacts on fatalities in earthquake-prone areas. We present a global analysis of the changes in population size and urban land area in earthquake-prone areas from 1990 to 2015, and their impacts on earthquake-related fatalities. We found that more than two thirds of population growth (or $70 \%$ of total population in 2015) and nearly three quarters of earthquake-related deaths (or 307,918 deaths) in global earthquake-prone areas occurred in developing countries with an urbanization ratio (percentage of urban population to total population) between 20 and $60 \%$. Holding other factors constant, population size was significantly and positively associated with earthquake fatalities, while the area of urban land was negatively related. The results suggest that fatalities
\end{abstract}

Qingxu Huang

qxhuang@bnu.edu.cn

1 State Key Laboratory of Earth Surface Processes and Resource Ecology, Beijing Normal University, Beijing 100875, China

2 School of Natural Resources, Faculty of Geographical Science, Beijing Normal University, Beijing 100875, China

3 Fenner School of Environment and Society, Australian National University, Canberra, ACT 2601, Australia

4 Department of Geography and Environmental Management, University of Waterloo, Waterloo, Ontario N2L 3G1, Canada

5 Academy of Disaster Reduction and Emergency Management, Ministry of Emergency Management and Ministry of Education, Beijing Normal University, Beijing 100875, China increase for areas where the urbanization ratio is low, but after a ratio between 40 and $50 \%$ occurs, earthquake fatalities decline. This finding suggests that the resistance of building and infrastructure is greater in countries with higher urbanization ratios and highlights the need for further investigation. Our quantitative analysis is extended into the future using Shared Socioeconomic Pathways to reveal that by 2050 , more than $50 \%$ of the population increase in global earthquake-prone areas will take place in a few developing countries (Pakistan, India, Afghanistan, and Bangladesh) that are particularly vulnerable to earthquakes. To reduce earthquake-induced fatalities, enhanced resilience of buildings and urban infrastructure generally in these few countries should be a priority.

Keywords Earthquake risk - Global South · Risk governance · Urbanization ratio · Urban sustainability

6 School of Geographical Science, Qinghai Normal University, Xining 810016, China

7 Key Laboratory of Land Surface Pattern and Simulation, Institute of Geographic Sciences and Natural Resources Research, Chinese Academy of Sciences, Beijing 100101, China

8 Department of Geography, University of Washington, Seattle, WA 98195, USA

9 School of Social Sciences, Nanyang Technological University, Singapore 639818, Singapore

10 Geophysical Institute and Center for Disaster Management and Risk Reduction Technology, Karlsruhe Institute of Technology (KIT), 76344 Karlsruhe, Germany 


\section{Introduction}

The process of urbanization remains an ongoing global phenomenon. Migration to and concentration of global population in urban areas has reached $55 \%$ with an estimated 68\% level anticipated by 2050 (UN 2019). The outcome of this concentration of people, buildings, and other assets attributed to urbanization (Bloom et al. 2008) is an increase in the exposure of populations to natural catastrophes, for example, earthquakes (UN 2015), floods (Pesaresi et al. 2017), and disease spread (Alirol et al. 2011). Due to the high cost of living in proximity to urban area (Ravallion and van de Walle 1991; Shucksmith et al. 2009), the most vulnerable proportion of the population often lives in substandard residential building (Lankao and Qin 2011; UNHCR 2014; Nagendra et al. 2018).

While the growth of urban population is substantial (58\% increase in global urban population from 1990 to 2015), it has been outpaced by the rate of urban expansion (74\%) (Riahi et al. 2017; UNDP 2018). Urban expansion often involves the conversion of agriculture and forest lands to low-density, single-story, residential building land uses (Spence 2007; Güneralp et al. 2020). The speed of building creation on the urban periphery can lead to construction that is often of questionable quality (Green 2008; Oteng-Ababio 2012), since the focus of development is often on gaining affordable access to urban occupational opportunities and amenities (Bilham 2009) rather than the quality of living produced by development.

For developing countries, urbanization is usually accompanied by a growth in vulnerable buildings and infrastructure (Jackson 2006; Spence 2007; Ambraseys and Bilham 2011; Wyss 2018), because proper construction codes may be lacking or poorly implemented (Bilham 2004; Aitsi-Selmi et al. 2015). Developing countries also experience the fastest rate of urbanization (Jiang and O'Neill 2017; Chen et al. 2020a), with many of those fastgrowing urban areas located in earthquake-prone zonesup to $31 \%$ of global built-up areas (Pesaresi et al. 2017). While global changes in population (Leyk et al. 2019) and land-use (Potere and Schneider 2007) have been recorded and their association with urbanization quantified (Montgomery 2008; IPCC 2018), the relationship between urbanization in earthquake-prone areas and its impacts on earthquake fatalities is focused at the regional and city scales (Sarris et al. 2010; Abramson and Qi 2011; Martins et al. 2012; Huang et al. 2018).

Little is known about the relationship between earthquake fatalities and global urbanization (Peduzzi et al. 2009; Daniell et al. 2011; UN 2015). While population exposure to earthquakes has increased (Djordjević et al. 2016; He et al. 2016; Dou et al. 2018) and built-up surfaces in earthquake-prone areas have increased globally from 1975 to 2015 (Pesaresi et al. 2017), an examination of the relationship between population size or urban land area and earthquake fatalities is lacking. Exploring this relationship is critical to predicting seismic risks and mitigating earthquake fatalities.

To overcome this gap in knowledge, we quantify the changes in global population and urban land area in earthquake-prone places and their impacts on associated fatalities in the context of urbanization. We also discuss the implications of this study in the context of expected global urbanization under different Shared Socioeconomic Pathways (SSPs) in the future.

\section{Materials and Methods}

We used multiple sources of data to examine the changes in population and urban land in global earthquake-prone areas and their association with earthquake fatalities. First, we quantified the change in population and urban land in earthquake-prone settings from 1990 to 2015. Then, we examined the relationship between urbanization (that is, population, urban land, and the urbanization ratio) and earthquake fatalities in the earthquake-prone areas during 1990-2018, using a series of regression models and the STIRPAT (STochastic Impacts by Regression on Population, Affluence, and Technology) approach (York et al. 2003) in which fatalities are estimated as a function of hazard, exposure, and vulnerability (Lavell et al. 2012; UNISDR 2017).

\subsection{Data}

To quantify the changes in global population and urban land in the earthquake-prone areas we utilized four types of data. First, population and urban land data were acquired from the HYDE 3.2 dataset at $10 \mathrm{~km}$ resolution (Goldewijk 2016). The History Database of the Global Environment (HYDE) 3.2 dataset is the only global dataset generated using a consistent approach to estimate historical and future population and urban land dynamics. Gridded HYDE 3.2 population and urban land data for 1990 and 2015 as well as 2050 under five Shared Socioeconomic Pathways (SSPs) were used. We report the mean, maximum, and minimum values of the five SSP scenarios to depict uncertainties and variation in the future (O'Neill et al. 2014, 2017; van Vuuren et al. 2014).

Second, global peak ground acceleration (PGA) data were acquired to map earthquake-prone areas. Areas with a PGA equal to or greater than $0.2 \mathrm{~g}$ (gravitational acceleration), when the collapse probability of buildings starts to increase remarkedly, were defined as the earthquake-prone 
areas (Jaiswal et al. 2011a; Holzer and Savage 2013). The most updated PGA data and resulting map were used, which collated more than 30 national and regional maps from various institutions by the Global Earthquake Model (GEM) foundation (Pagani et al. 2018). The PGA data were generated using the OpenQuake engine (Pagani et al. 2014) and expert input by hundreds of global scientists and engineers over the last 20 years. Although the PGA map provided by the GEM may under or overestimate the PGA (Ishibe and Shimazaki 2012; Wyss 2015) and alternatives were proposed (for example, Panza and Bela 2020), it still remains the most up-to-date, only freely accessible, and widely used global map available (Gerstenberger et al. 2020).

Third, fatalities from earthquakes were derived from the global CATDAT (CATastrophy DATabase) database (Daniell et al. 2011), a catalog that emphasizes earthquakes, their triggering impacts, and downstream costs. Although alternative datasets on earthquake damage, such as the National Geophysical Data Center/World Data Service (NGDC/WDS 2018), Emergency Events Database (EM-DAT 2018), and PAGER-CAT (Prompt Assessment of Global Earthquakes for Response) catalog (Allen et al. 2009) datasets are available, CATDAT was used due to its accessibility, information completeness, and wide use. Furthermore, the CATDAT database is the largest known catalogue that has been validated against four major earthquake databases (PAGER-CAT, NGDC, UTSU (Utsu 2004), and MRNATHAN (Munich Re 2009)) earthquakeby-earthquake at the global scale including many other original data sources, which has resulted in substantial error reduction (Daniell et al. 2011). The CATDAT catalog records the impacts of damaging earthquakes, including direct and secondary effects since 1900 for over 9,900 earthquakes, from over 35,000 individual literature sources in 90 languages. Since it is difficult to quantify accurately the exact amount of earthquake damage, the database reports the preferred estimates and lower/upper bounds of earthquake damages after a careful analysis of all damage reports.

Fourth, auxiliary data on global administrative boundaries were obtained from the Resource and Environment Data Cloud Platform, Chinese Academy of Science. ${ }^{1}$ Socioeconomic data were obtained from the World Bank. ${ }^{2}$ All gridded data were reprojected to the Albers projection with a spatial resolution of $10 \mathrm{~km}$.

\footnotetext{
${ }^{1}$ https://english.cas.cn/research/database/.

2 https://databank.worldbank.org/databases.
}

\subsection{Examining the Impacts of Urbanization on Fatalities in Earthquake-Prone Areas}

Fatalities caused by earthquakes are typically estimated as a function of the earthquake hazard (mainly from ground shaking, but also from landslides and tsunami), the size of the population impacted, number of buildings exposed to earthquakes, and the vulnerability of exposed population and buildings (Lavell et al. 2012; UNISDR 2017). Similar to other approaches (for example, Peduzzi et al. 2009; Li et al. 2015), nationally reported data were used to represent these three components (hazard, exposure, and vulnerability). In terms of the seismic hazard, we chose the extent of the earthquake-prone areas, and the average depth and magnitude of earthquakes in the earthquake-prone areas during 1990-2015 for each country. For exposure to earthquakes, we used the average population and the average urbanized land in the earthquake-prone areas between 1990 and 2015.

Vulnerability is difficult to quantify globally in the absence of extensive building inventories and substantial socioeconomic data (Jaiswal and Wald 2010). When mapped globally, vulnerability is typically aggregated from national scale variables that act as proxies for specific variables of interest (Ruiter et al. 2017; Ward et al. 2020). Quantifying and mapping global vulnerability to earthquakes require the same approach as local factors, such as building quality and code, which are not always available at the national scale (Jaiswal and Wald 2010). To overcome this data gap, indicators such as the human development index (HDI) (Jaiswal et al. 2011b; Li et al. 2015) and vulnerability code (Daniell et al. 2011) are typically used.

We opted to use a five-class vulnerability code developed by the USGS (United States Geological Survey) for inclusion in their Prompt Assessment of Global Earthquakes for Response (PAGER) system (Jaiswal et al. 2011a). The vulnerability code is strongly correlated ( $r=$ $-0.55, p<0.01$ ) with HDI and considers the materials and methods used for building construction as well as the efforts and capacity to respond to earthquake disasters.

To estimate the impacts of urbanization in earthquakeprone areas on fatalities, fatalities were estimated, as in previous studies (Peduzzi et al. 2009; Li et al. 2015), by using a simple multiplicative function combining hazard, exposure, and vulnerability. Similar to the widely used environmental impact $=f$ (population, affluence, technology) or IPAT model (York et al. 2003), we used the STIRPAT approach (York et al. 2003) to develop four models to examine the relative influence of each of the three components and their relationship with urbanization on earthquake fatalities. 
The four models were used to examine the impacts of hazard, exposure, vulnerability, and urbanization on earthquake fatalities. First, we used a parsimonious model (Model I-hazard and vulnerability) to account for the impacts of hazard and vulnerability. The equation for this model can be expressed as follows:

$\ln ($ death $)=\alpha_{1} \ln ($ hazard $)+\alpha_{2} \ln ($ vulnerability $)+\mathrm{e}$

where the hazard was represented by the extent of the earthquake-prone areas and the average depth and magnitude of earthquakes in the earthquake-prone areas for each country, and vulnerability was denoted by the USGS vulnerability code. All the variables were used in their logarithmic form.

Then, we incorporated the effects of population and urban land exposure as follows:

$$
\begin{aligned}
\ln (\text { death })= & \alpha_{1} \ln (\text { hazard })+\alpha_{2} \ln (\text { vulnerability }) \\
& +\alpha_{3} \ln (\text { exposure })+\mathrm{e}
\end{aligned}
$$

in Model II-population exposure and Model III—urban land exposure.

Based on previous findings (Jackson 2006; Spence 2007; Ambraseys and Bilham 2011), we expected an inverted Ushaped relationship between urbanization ratio and earthquake fatalities. To test this conjecture, we added the urbanization ratio and its quadratic term (both in logarithmic form) to generate Model IV-urbanization ratio, following the well-known environmental Kuznets curve hypothesis, expressed as follows:

$$
\begin{aligned}
\ln (\text { death })= & \alpha_{1} \ln (\text { hazard })+\alpha_{2} \ln (\text { vulnerability }) \\
& +\alpha_{3} \ln (\text { exposure })+\alpha_{4} \ln (\text { ur }) \\
& +\alpha_{5}(\ln (\text { ur }))^{2}+\mathrm{e}
\end{aligned}
$$

When $\alpha_{4}$ is significantly positive and $\alpha_{5}$ is significantly negative, an inverted U-shaped relationship between fatalities and urbanization ratio can be confirmed. Changing the values of $\alpha_{4}$ and $\alpha_{5}$ can affect the shape of the inverted U-shaped curve between urbanization ratio and deaths.

In examining the global relationship between urbanization and earthquake-induced fatalities, our analysis is constrained to a relatively short time period of 25 years with data comprising a large amount of uncertainty. In terms of data uncertainty, we report the upper and lower bounds of fatalities of our regression results based on the CATDAT catalogue. In addition to the analysis using all the available data, we conducted an extra analysis by excluding fatalities from catastrophic earthquakes (for example, the 2010 Haiti earthquake) as the recorded fatalities are highly controversial (Doocy et al. 2013a), and the results are similar to our original analysis.

\section{Results}

We report the characteristics of earthquake-prone areas, the changes in population and urban land in earthquake-prone areas, and the relationship between exposure change and earthquake fatalities in this section.

\subsection{Earthquake-Prone Areas}

Total global earthquake-prone area was estimated to cover $1.36 \times 10^{7} \mathrm{~km}^{2}$, representing $9.2 \%$ of global terrestrial area (Figs. 1,2). These areas were unevenly distributed globally with the largest proportion of earthquake-prone areas concentrated in several countries along the CircumPacific Belt and the Mediterranean-Asiatic Belt, corroborating others (England and Jackson 2011; Bilham 2014; Liu and Stein 2016). A total of 94 countries have earthquake-prone areas. Among these countries, the 10 countries (Iran, China, Peru, Indonesia, India, Pakistan, United States, Argentina, Chile, and Turkey) with the largest amount of earthquake-prone area have a total area of $7,730,000 \mathrm{~km}^{2}$, accounting for approximately $57 \%$ of the globe's earthquake-prone areas.

People living in global earthquake-prone areas were subject to disproportionally high levels of earthquake risk (Fig. 2). Globally, only a small proportion of population and urban land $(20.8 \%$ and $15.5 \%$, respectively) were located in earthquake-prone areas. Yet more than $56 \%$ of the earthquakes that caused casualties, nearly half of deaths caused by earthquakes, and more than $91 \%$ of deaths resulting from building collapse worldwide from 1900 to 2018 were attributed to earthquakes occurring in these earthquake-prone areas.

While only $9.2 \%$ of the global areas affected by earthquakes experience these higher levels of ground acceleration, $47.8 \%$ of all earthquake deaths and $91.7 \%$ of all deaths due to shaking reside within these earthquake-prone areas. Average population and urban land data between 1990 and 2015 are used to depict population and urban land exposure. Earthquakes, total deaths, and shaking deaths refer to the number of earthquakes, the total deaths and shaking deaths of earthquakes, respectively, during 1900-2018 recorded by CATDAT.

\subsection{Population Change in Global Earthquake-Prone Areas from 1990 to 2015}

The population in global earthquake-prone areas increased at a faster rate than the global population (Table 1). The rate of population increase was $40.2 \%$ in global earthquake-prone areas, rising from 1075.94 million in 1990 to 1508.79 million in 2015. During the same period, global 
Fig. 1 Global distribution of earthquake-prone areas

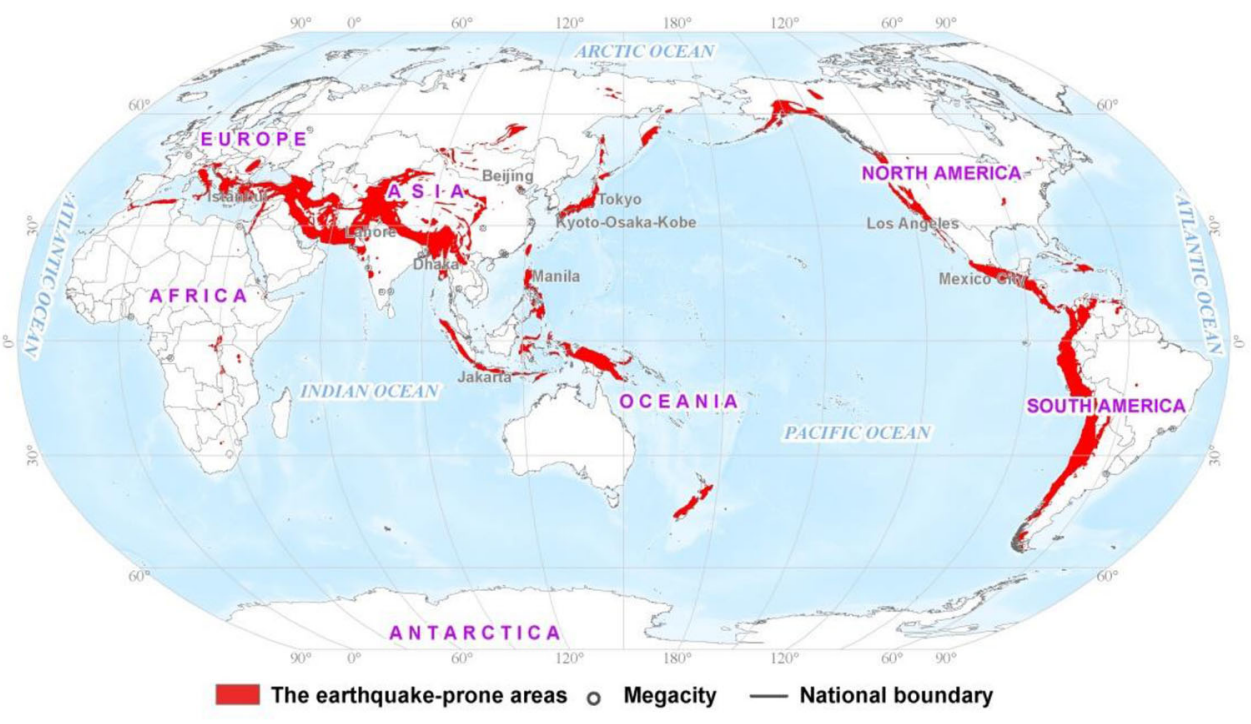

Fig. 2 Characteristics of earthquake-prone areas and their impacts relative to areas outside earthquake-prone areas. Bars represent totals associated with all earthquakes while the proportion delineated in orange represents those in earthquakeprone areas (that is, with a peak ground acceleration equal to or greater than 0.2 gravitational acceleration; see the Data section (Sect. 2.1) for details). Data source CATDAT

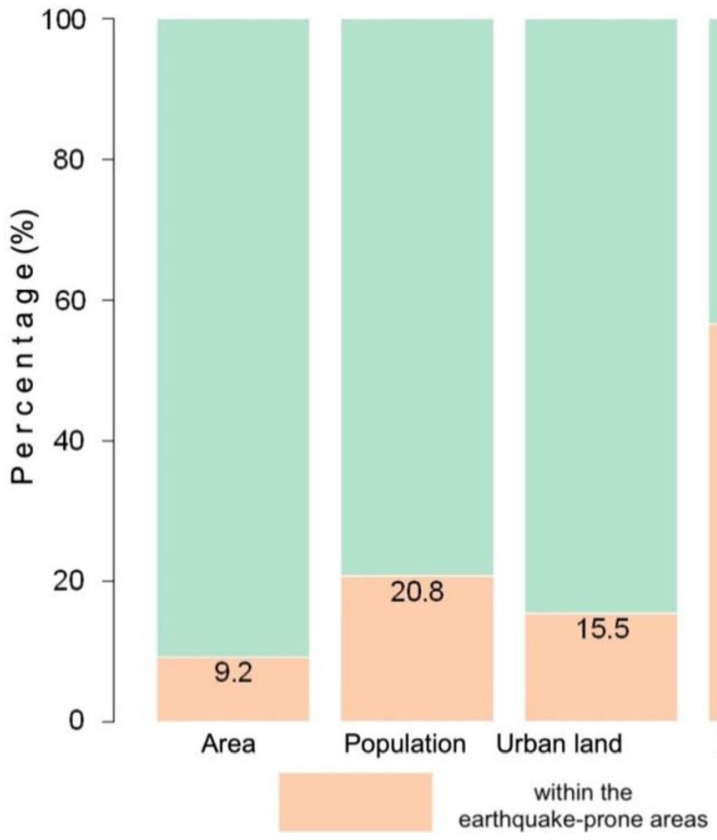

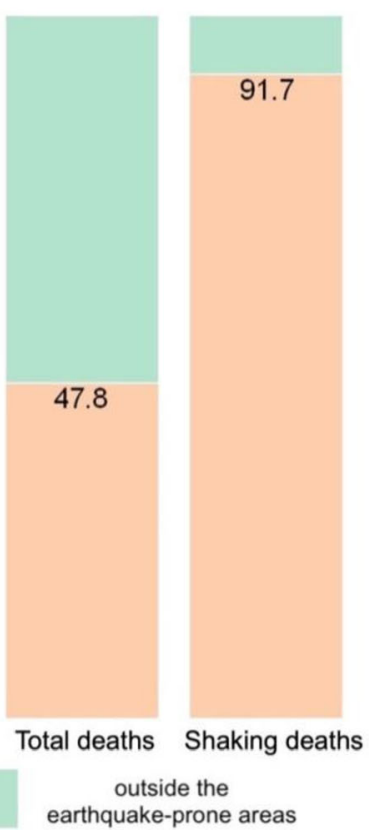

population increased by $36.6 \%$. The result of a $9 \%$ faster growth rate of population in earthquake-prone areas is that, in 2015 , those areas held more than $1 / 5$ of the global population.

The population residing in urban areas relative to the total population of a country, or other spatial unit, defines a measurement known as the urbanization ratio (UN 2019). Population increases in global earthquake-prone areas were concentrated in countries with a relatively low urbanization ratio (Table 1, Fig. 3). Among the 94 countries that have earthquake-prone areas, more than $2 / 3$ of the population increase from 1990 to 2015 occurred in these areas within 43 countries that have a low urbanization ratio (between 20 and $60 \%$ ). The average earthquake-prone area population increase of the 43 countries $(47.8 \%)$ was 1.2 times the average global population increase for all earthquake-prone areas. While rates of population increase in earthquakeprone areas were high, they were also highly variable (ranging from 37 to $72 \%$ ). Furthermore, countries with the highest urbanization ratio had the lowest rate of population increase in earthquake-prone areas. Only those countries with the highest urbanization ratios-80-100\%, for example, the United States, New Zealand, and Japan-had a rate of population increase $(16.0 \%)$ substantially less than the global rate $(36.6 \%)$.

For the five countries with the largest growth in earthquake-prone-area population (that is, India, Pakistan, Indonesia, the Philippines, and Bangladesh), the rate of 
Table 1 Changes in population and urban land in global earthquake-prone areas from 1990 to 2015

\begin{tabular}{|c|c|c|c|c|c|c|}
\hline \multirow[t]{2}{*}{ Regions } & \multicolumn{3}{|c|}{ Population (million) } & \multicolumn{3}{|c|}{ Urban land $\left(\mathrm{km}^{2}\right)$} \\
\hline & 1990-2015 & 2015 & Rate of change (\%) & $1990-2015$ & 2015 & Rate of change (\%) \\
\hline Global earthquake-prone areas & 432.82 & $1,508.80$ & 40.2 & 38,491 & 93,857 & 69.2 \\
\hline $0<U R \leq 20 \%$ & 17.47 & 40.81 & 74.9 & 232 & 329 & 239.2 \\
\hline $20 \%<U R \leq 40 \%$ & 192.74 & 529.66 & 57.2 & 4,197 & 9,380 & 81.0 \\
\hline $40 \%<U R \leq 60 \%$ & 100.78 & 377.51 & 36.4 & 7,499 & 16,070 & 87.5 \\
\hline $60 \%<U R \leq 80 \%$ & 95.48 & 369.91 & 34.8 & 15,228 & 30,156 & 102.0 \\
\hline $80 \%<U R \leq 100 \%$ & 26.35 & 190.91 & 16.0 & 11,245 & 37,932 & 42.1 \\
\hline World & $1,911.93$ & $7,142.50$ & 36.6 & 204,415 & 572,424 & 55.6 \\
\hline Proportion* & $0.5 \%$ & $21.1 \%$ & - & $1.4 \%$ & $16.4 \%$ & - \\
\hline
\end{tabular}

Average urbanization ratio $(U R)$, which is the percentage of urban population to total population in 2015

*This proportion refers to the percentage of the amount in global earthquake-prone areas to global amount

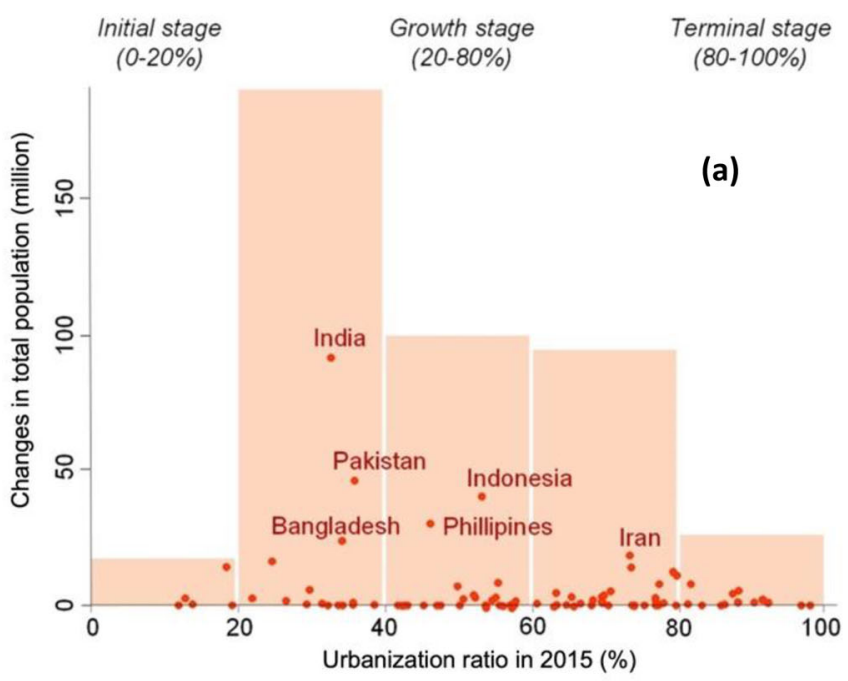

Fig. 3 Relationship between seismic exposure change and urbanization ratio in global earthquake-prone areas. a Population; b urban land. Scatterplots represent changes in total population or urban land for each country, while the bars represent the aggregated change for countries within each interval of urbanization ratio. According to the

population increase ranged from $37 \%$ to $72 \%$ and the total growth accounted for more than half of the global growth in earthquake-prone area population (Figs. 3a, 4a). It is no coincidence that all five of these countries reside in Asia. Seismic faults interface with drinking water sources along the Mediterranean-Asiatic Belt. These faults act as aquifers for many semiarid and arid countries in the Middle East and Central Asia, India, Pakistan, and Bangladesh (Jackson 2006). The combination of drinking water sources with the rapid population growth of Southeast Asian countries (for example, Indonesia and the Philippines) has led to the location of vulnerable populations along the Circum-Pacific Seismic Belt (UNHCR 2014).

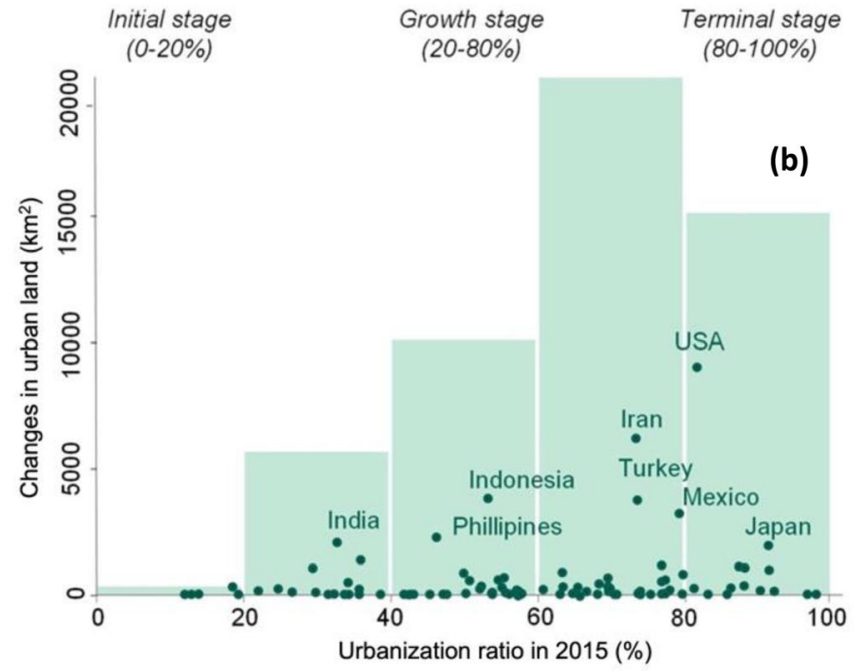

Northam Curve (Northam 1979; Mulligan 2013), the urbanization ratio of a nation can be divided into at least three stages, that is, the initial stage with an urbanization ratio between 0 and $20 \%$, the growth stage with an urbanization ratio between $20 \%$ and $80 \%$, and the terminal stage with a ratio above $80 \%$

Countries with earthquake-prone areas and low or high urbanization ratios (0-20\% and 80-100\%) in 2015 experienced low levels of population growth (Fig. 3). While the absolute population increase among the five countries with a low urbanization ratio only accounted for just over 17 million, their average rate of change was over 74\% between 1990 and 2015. In contrast, the 14 countries with the highest urbanization ratio held an average population growth rate of $16 \%$, substantially lower than the $37 \%$ global average (Fig. 3, Table 1). 


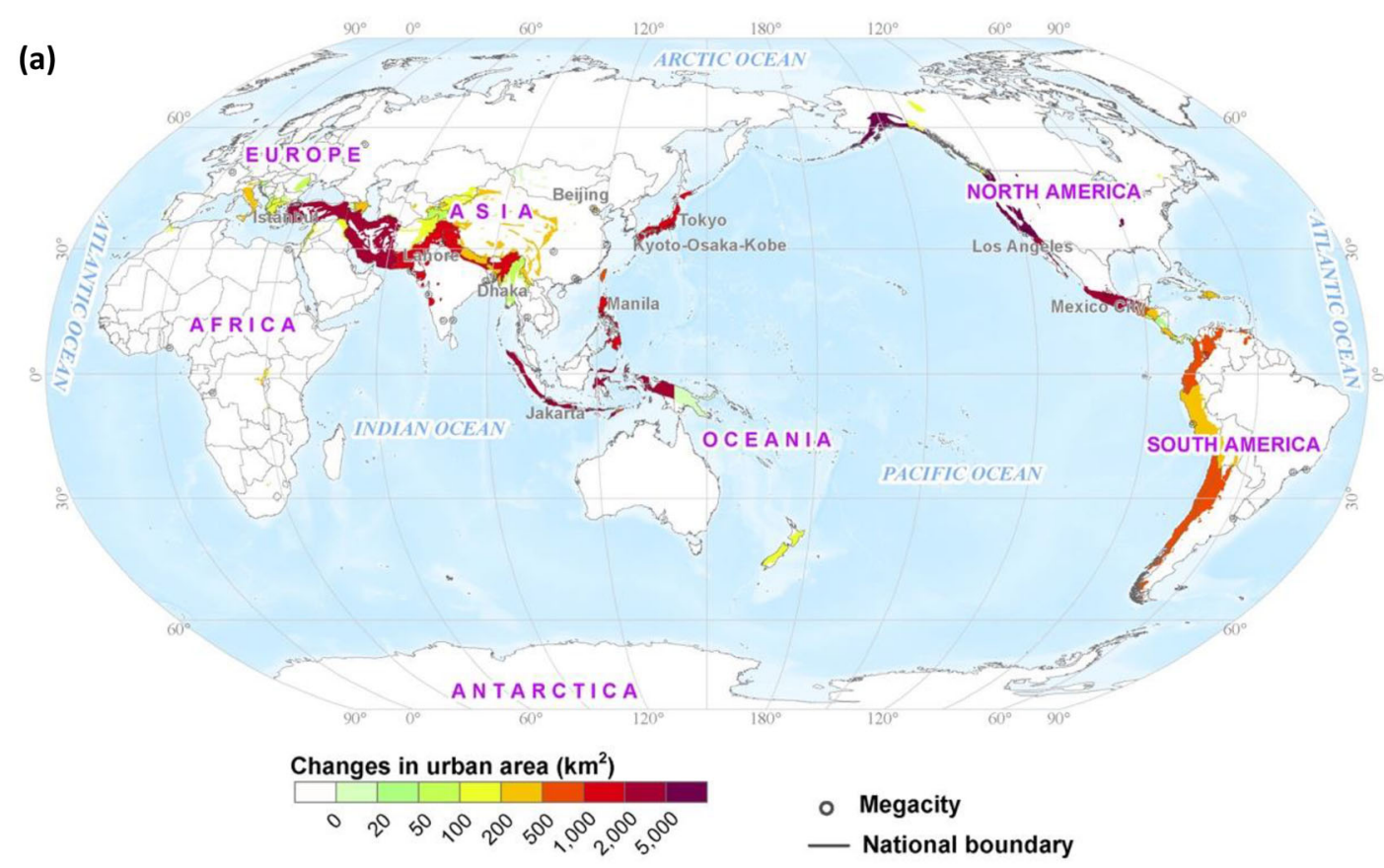

(b)

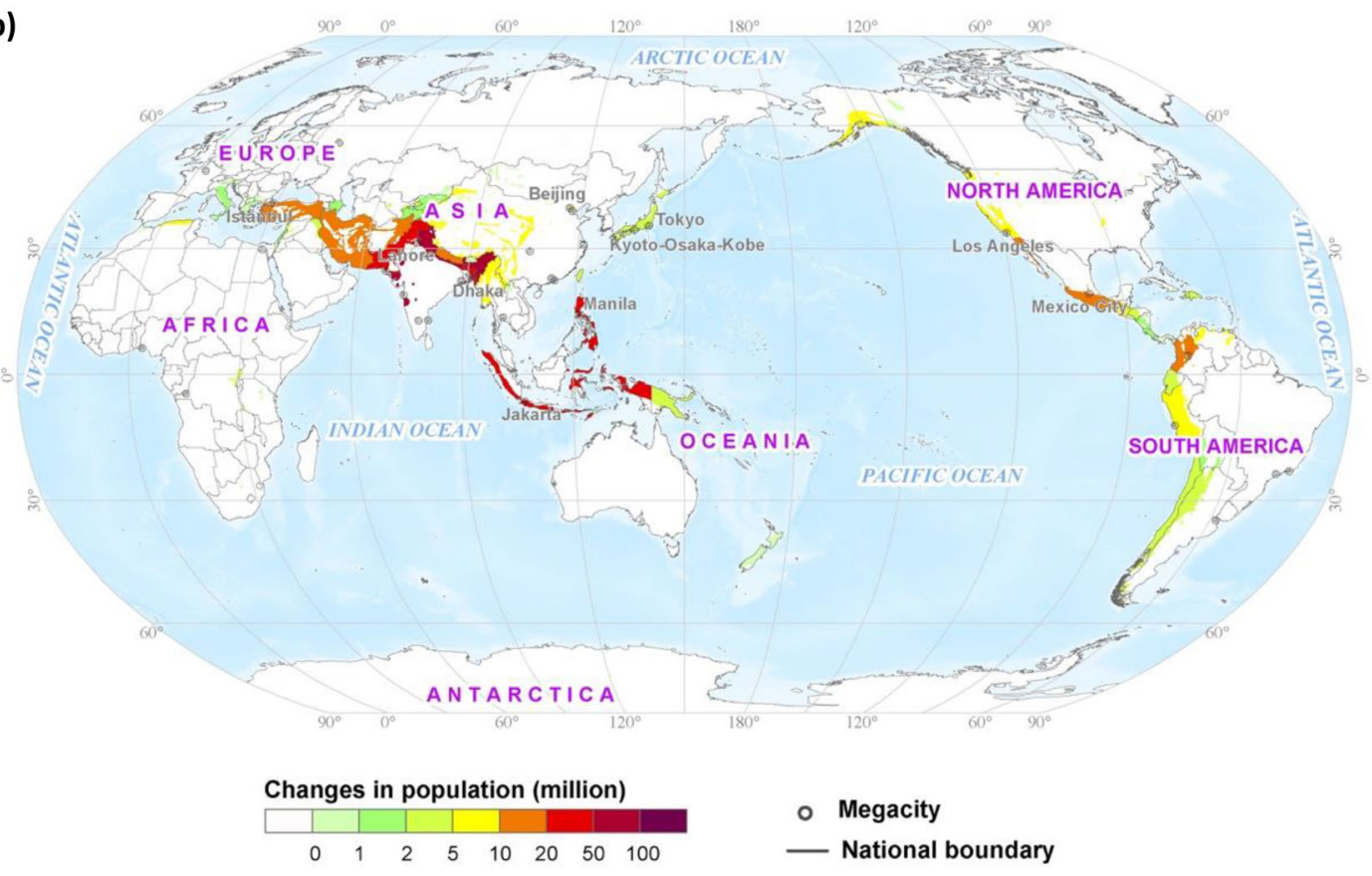

Fig. 4 The global distribution of changes in population (a) and urban land (b) in earthquake--prone areas between 1990 and 2015

\subsection{Urban Land Change in Global Earthquake- Prone Areas from 1990 to 2015}

Land area classified as urban increased faster than population in global earthquake-prone areas from 1990 to 2015 (Table 1). The urban lands in global earthquake-prone areas expanded from $55,466 \mathrm{~km}^{2}$ in 1990 to $93,867 \mathrm{~km}^{2}$ in 2015 , representing an increase of $69.2 \%$. This increase was
1.7 times greater than the increase in population in those same areas. In addition, the expansion of urban lands in global earthquake-prone areas was 1.2 times greater than the global urban expansion. Consequently, the percentage of global urban land located in the global earthquake-prone areas increased from $15.1 \%$ to $16.8 \%$ from 1990 to 2015 .

In contrast to the rate of population increase being greatest in earthquake-prone areas in countries with 
20-60\% urbanization ratio, the increase in global urban earthquake-prone land area was concentrated in a small number of countries with high urbanization ratios (60-100\%) (Fig. 3b). Among the 94 countries with earthquake-prone areas, nearly $69 \%$ of the increased urban land in global earthquake-prone areas occurred in 46 countries with an urbanization ratio greater than $60 \%$ in 2015 . The total growth of urban land in these countries' earthquakeprone areas reached $26,473 \mathrm{~km}^{2}$ and the corresponding rate of increase was $63.6 \%$, which is similar to the average rate in the earthquake-prone areas throughout the world. Among the 46 countries, the top five countries that experienced the largest increases of urban land in their earthquake-prone areas were the United States (48.4\%), Iran (742.3\%), Turkey (340.7\%), Mexico (118.7\%), and Japan (15.7\%). The cumulative outcome of urban expansion in these five countries amounted to $17,872 \mathrm{~km}^{2}$, more than 12 times the earthquake-prone area urban expansion in Japan.

Large increases of urban land area in earthquake-prone areas also occur in some countries with an urbanization level lower than $60 \%$, such as Indonesia, the Philippines, and India (Figs. 3b, 4b). The corresponding increases in urban land in the three countries' earthquake-prone areas were 2821,1673 , and $1524 \mathrm{~km}^{2}$, respectively, and all of them are developing countries in Asia. The growth of urban land in the earthquake-prone areas of the five countries with a low level of urbanization (urbanization ratio between 0 and 20\%) was marginal, with a total amount of $232 \mathrm{~km}^{2}$, or $0.4 \%$ of the total growth in global earthquakeprone areas.

Earthquake-prone area urban land expanded slower in countries with a high urbanization ratio $(80-100 \%)$ than countries with a lower level of urbanization ratio (Table 1). This difference suggests that to fulfill increasing residential demands in the earthquake-prone areas of developing countries more multistory buildings and crowded informal settlements are frequently constructed (Frolking et al. 2013; Henderson et al. 2016). The lack of building codes and guidelines for coping with earthquake strikes and postdisaster management put these vulnerable populations in danger (Doberstein and Stager 2013).

\subsection{Earthquake Fatalities in Global Earthquake- Prone Areas during 1990-2018}

Earthquake fatalities in global earthquake-prone areas during 1990-2018 for the 94 countries at risk were estimated at 413,576, with lower and upper bounds of 378,152 and 516,722, respectively (see Sect. 2.1 Data for the explanation of the lower/upper bounds). The top five countries that had the largest numbers of earthquake fatalities in their earthquake-prone areas were China, Pakistan, Haiti, India, and Afghanistan. Their earthquake fatalities in the earthquake- prone areas during this period were $88,710,87,698,80,009,28,912$, and 11,561 , respectively, which together accounted for $71 \%$ of total deaths in global earthquake- prone areas. These countries had an urbanization ratio below $60 \%$ in 2015 and belong to the group of countries most vulnerable to earthquakes (Fig. 5).

As one would expect, earthquake fatalities were concentrated in the most vulnerable countries (Fig. 5). However, the proportion of all earthquake fatalities in these countries is striking. Approximately $96 \%$ (96.1-97.0\%) of all deaths in global earthquake-prone areas occurred in countries (33) classified with the highest vulnerability score (a vulnerability code of 4 or 5). Seven of these countries (Pakistan, China, Iran, India, Afghanistan, Nepal, and Bangladesh) had the highest level of vulnerability (vulnerability code of 5) with total earthquake fatalities in earthquake-prone areas reaching 305,286 (280,531-321,280), accounting for approximately $74 \%$ (62.2-74.2\%) of all fatalities in global earthquake-prone areas. The average number of deaths per thousand residents in countries with the highest level of vulnerability was 5.77 (5.30-6.07), which is 11.5 times (11.3-12.1) greater than the three countries with the lowest classification of vulnerability (New Zealand, Japan, and the United States).

The death rates per thousand population were disproportionally higher in countries with a low urbanization ratio and a high level of vulnerability (Fig. 6). The average number of deaths per thousand people in global earthquake-prone areas was $4.11(3.79-5.37)$ in countries with an urbanization ratio below $60 \%$. The average number of deaths per thousand people was nearly half (2.11) in countries with an urbanization ratio above $60 \%$ (1.88-2.36). Similarly, average deaths per $\mathrm{km}^{2}$ urban land in global earthquake-prone areas was 10 times higher in countries with an urbanization ratio below $60 \%, 17.8$ per $\mathrm{km}^{2}$ (16.4-23.2), than those above $60 \%$ (1.9 per $\mathrm{km}^{2}$, or 1.7-2.0). The average deaths per $\mathrm{km}^{2}$ of urban land in countries with the highest vulnerability (vulnerability codes of 4 and 5) was 140 times (137-147) greater than what was found in the three countries with the lowest vulnerability.

\subsection{The Relationship Between Urbanization and Earthquake Fatalities}

Overall, the average population living in earthquake-prone areas during 1990-2015 and the extent of the earthquakeprone areas were found to be significantly and positively associated with earthquake fatalities (Table 2). The correlation coefficient between these two variables and earthquake induced deaths were 0.66 and 0.58 , which were the most influential among eight tested variables (Table 2). A regression analysis further confirmed that the amount of 
Fig. 5 Distribution of the fatalities caused by earthquakes in the earthquake-prone areas of countries during 1990-2018.

Vulnerability was attributed using the vulnerability code in the USGS' PAGER (https:// earthquake.usgs.gov/data/pager/ ) system (see the Methods section (Sect. 2.2) for details)

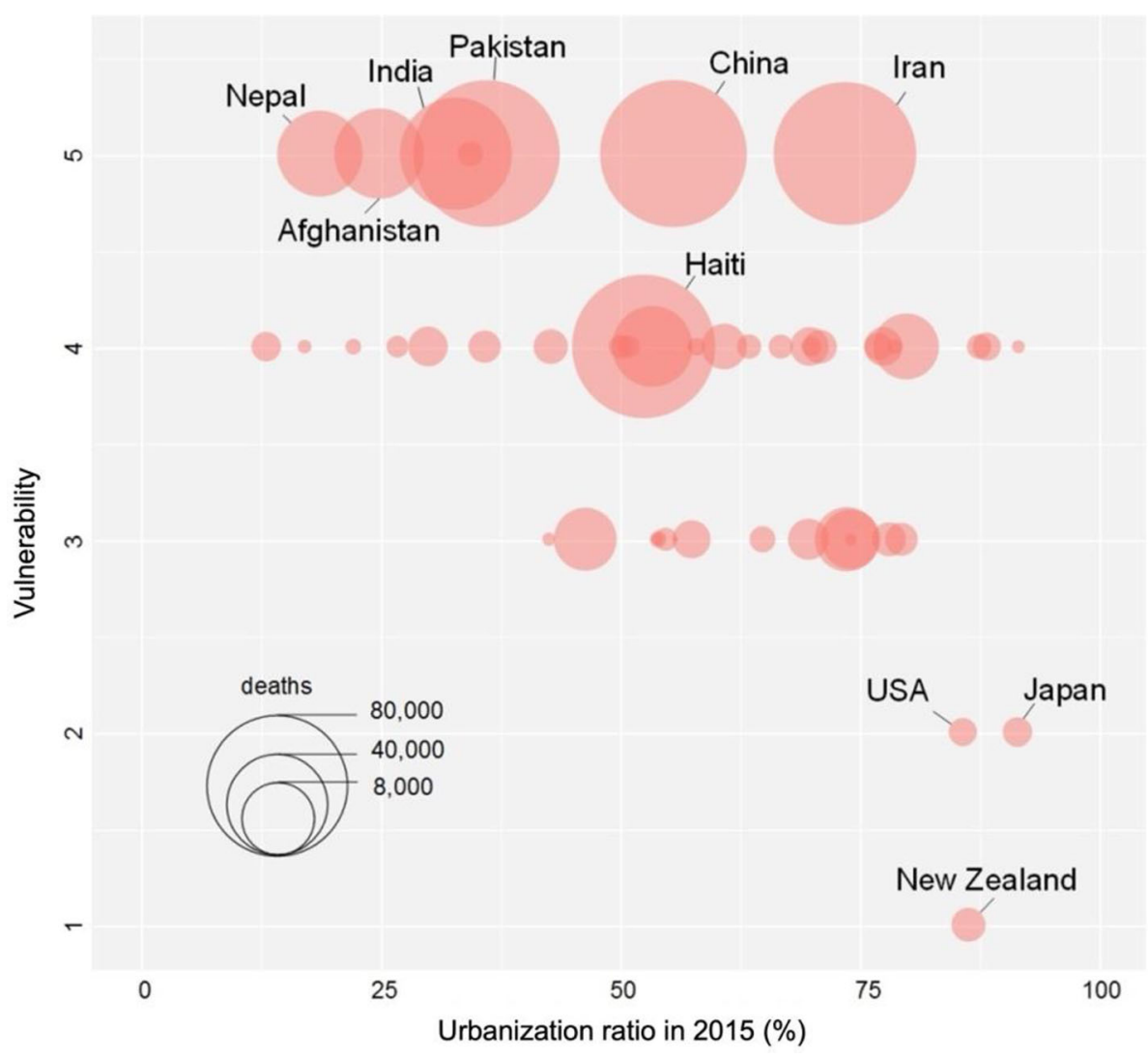

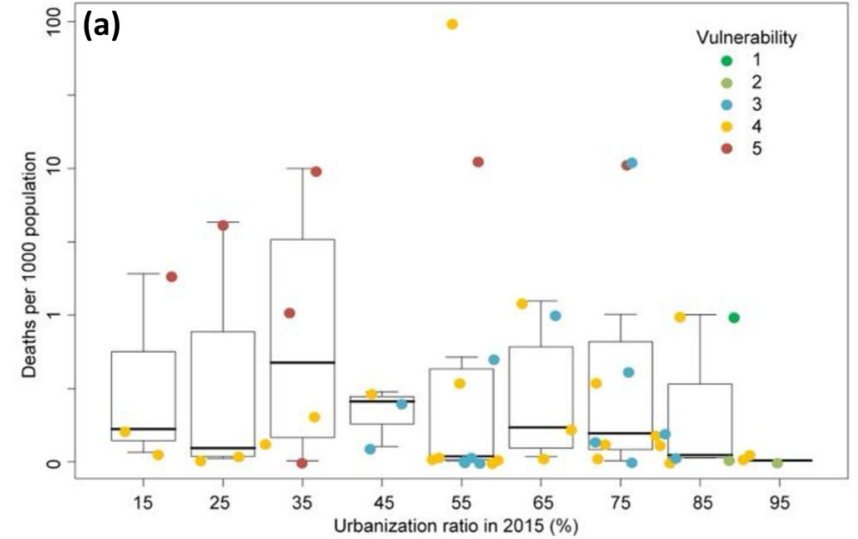

Fig. 6 Distribution of the average deaths caused by earthquakes per thousand population (a) and per $\mathrm{km}^{2}$ of urban land (b) in global earthquake-prone area The dots represent the values for each country and the boxes represent the ranges of values within each $10 \%$ interval

population in the earthquake-prone areas and the extent of the earthquake-prone areas were positively associated with fatalities caused by earthquakes.

Standardized regression coefficients for the average population in earthquake-prone areas varied from 0.53 to 0.92 from Model II to Model IV, whereas the coefficients for the extent of the earthquake-prone area were 0.31 and

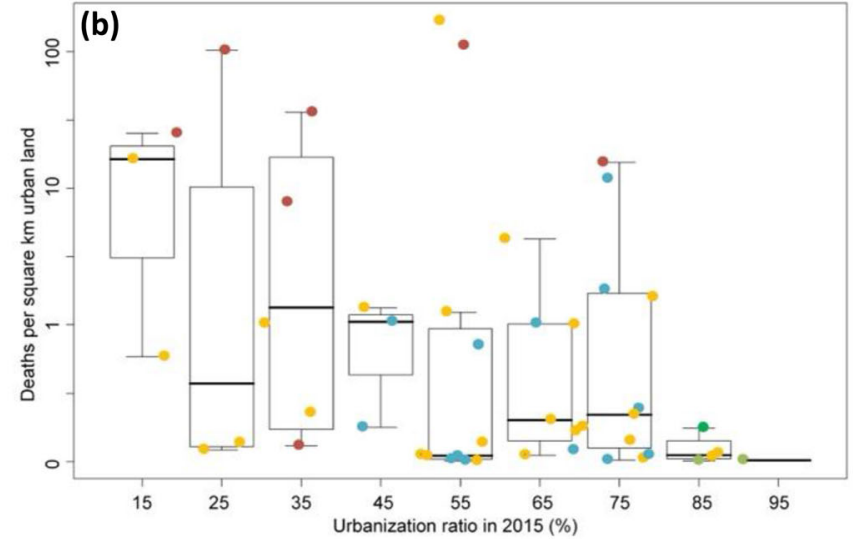

of urbanization ratio (for example, 10-20\% for the first box). Vulnerability was attributed using the vulnerability code in the PAGER system by USGS (see the Methods section (Sect. 2.2) for details)

0.60 in Model IV and Model I, respectively. In contrast, an increase in the average depth of earthquakes was significant and negatively associated with fatalities (Model I-IV), with standardized coefficients between -0.25 and -0.32 . An increase in average amount of urban land in the earthquake-prone areas was significantly and negatively associated with earthquake deaths, whereby standardized 
Table 2 Factors included in a regression analysis and their association with earthquake fatalities in the earthquake-prone areas

\begin{tabular}{|c|c|c|c|c|c|}
\hline Category & Variables & $\begin{array}{l}\text { Model I } \\
\text { Beta ( } p \text { value) }\end{array}$ & Model II & Model III & Model IV \\
\hline \multirow[t]{6}{*}{ Hazard } & \multirow[t]{2}{*}{ Earthquake-prone area $\left(\mathrm{km}^{2}\right)$} & $0.597 * *$ & 0.197 & 0.216 & $0.308^{+}$ \\
\hline & & $(0.000)$ & $(0.252)$ & $(0.198)$ & $(0.083)$ \\
\hline & \multirow[t]{2}{*}{ Average earthquake magnitude } & 0.080 & 0.135 & 0.143 & 0.183 \\
\hline & & $(0.560)$ & $(0.289)$ & $(0.249)$ & $(0.175)$ \\
\hline & \multirow[t]{2}{*}{ Average earthquake depth (km) } & $-0.249^{+}$ & $-0.273 *$ & $-0.304^{+}$ & $-0.321^{+}$ \\
\hline & & $(0.066)$ & $(0.029)$ & $(0.014)$ & $(0.010)$ \\
\hline \multirow[t]{2}{*}{ Vulnerability } & \multirow[t]{2}{*}{ Vulnerability code } & $0.211^{+}$ & 0.135 & -0.005 & -0.084 \\
\hline & & $(0.096)$ & $(0.253)$ & $(0.972)$ & $(0.556)$ \\
\hline \multirow[t]{4}{*}{ Exposure } & \multirow[t]{2}{*}{ Average population $1990-2015$} & & $0.527 * *$ & $0.816^{* *}$ & $0.916^{* *}$ \\
\hline & & & $(0.004)$ & $(0.001)$ & $(0.002)$ \\
\hline & \multirow[t]{2}{*}{ Average urban area $1990-2015\left(\mathrm{~km}^{2}\right)$} & & & $-0.360^{+}$ & $-0.580^{+}$ \\
\hline & & & & $(0.062)$ & $(0.051)$ \\
\hline \multirow[t]{6}{*}{ Urbanization } & \multirow[t]{2}{*}{ Urbanization ratio in $2015(\%)$} & & & & $2.964^{+}$ \\
\hline & & & & & $(0.087)$ \\
\hline & \multirow[t]{2}{*}{ Squared urbanization ratio of 2015} & & & & $-2.899^{+}$ \\
\hline & & & & & $(0.091)$ \\
\hline & $R^{2}$ & $40.9 \%$ & $51.2 \%$ & $55.1 \%$ & $58.2 \%$ \\
\hline & Akaike Information Criterion & 94.89 & 87.24 & 85.16 & 85.52 \\
\hline
\end{tabular}

The number of samples used for the regression was 50 because some countries did not have earthquake with fatalities during the studied period. The values in bracket are the $p$ values

${ }^{* *} p<0.01 ; * p<0.05 ;{ }^{+} p<0.1$

coefficients of -0.36 and -0.58 were acquired by Model III and IV, respectively. These findings corroborate existing literature, where population exposure and seismic hazard were strongly associated with earthquake fatalities (Jackson 2006; Peduzzi et al. 2009; Jaiswal et al. 2011b).

The introduction of the urbanization ratio and its quadratic term (Model IV) improved model fit. The eight variables in Model IV explained 58.2\% of the cross-national variance in earthquake fatalities in the earthquakeprone areas, while the most parsimonious model (Model I), which only considered the impacts of the hazard and vulnerability, explained $40.9 \%$ of the variance. These results confirm that urbanization is critically related to earthquake fatalities. More importantly, the coefficient between the number of fatalities caused by earthquakes and the urbanization ratio is significant and positive, whereas the coefficient for the quadratic term of urbanization ratio is significant and negative, which suggests that an inverted $U$ relationship similar to the environmental Kuznets curve (York et al. 2003) may exist. When the three components of risk (hazard, exposure, and vulnerability) are held constant, an increase in low to moderate levels of the urbanization ratio produces an increase in earthquake fatalities. When the urbanization ratio is moderate to high, however, a further increase in the urbanization ratio produces a decrease in earthquake fatalities (Fig. 7). The transition or point of inflection is estimated to occur when the urbanization ratio reaches around $44 \%$. Twenty-four countries have an urbanization ratio $\leq 44 \%$; all are developing countries and all are located in Africa or Asia, with the exception of Papua New Guinea. These countries are still experiencing increasing seismic risk and will continue to do so if earthquake fatality mitigation strategies are not improved upon and operationalized.

\section{Discussion}

The potential causes for the nonlinear relationship between urbanization and earthquake fatalities, and its implications for mitigating earthquake risk in the future, are discussed in this section.

\subsection{The Relationship Between Urbanization and Earthquake Fatalities}

The nonlinear relationship between urbanization and earthquake fatalities may partly be a function of population 


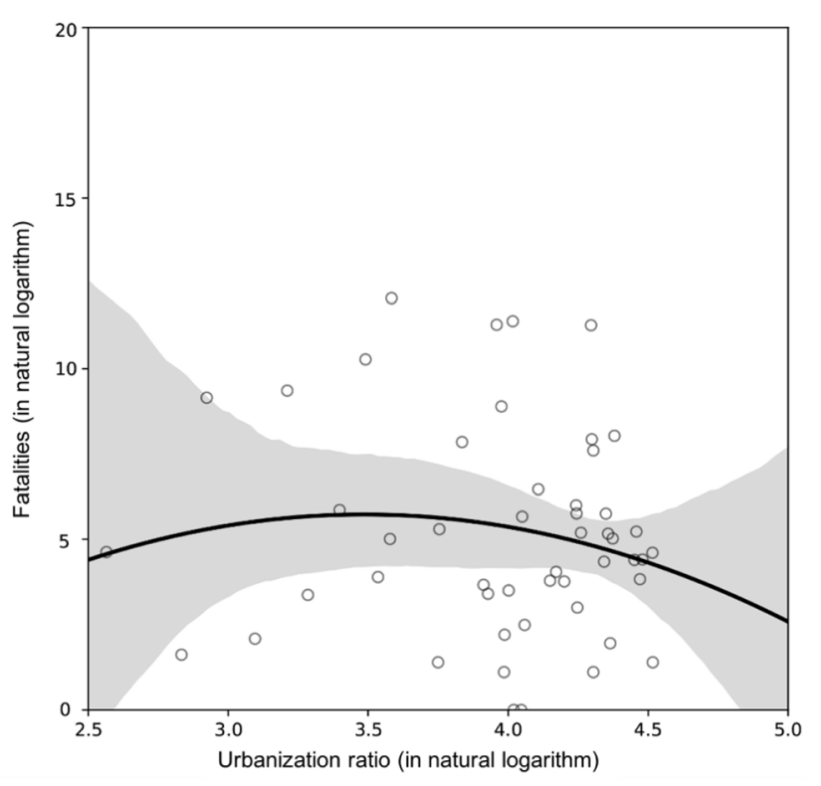

Fig. 7 Illustration of urbanization ratio inflection point for earthquake fatalities. The coefficients for the urbanization ratio and its squared form in the regression model (Model IV) are 19.42 and -2.56 , respectively. It can be estimated that the inflection point of the urbanization ratio for earthquake fatalities is at $\mathrm{e}^{\left(a_{4} /-2 a_{5}\right)}=$ $\mathrm{e}^{(19.42 / 2 / 2.56)}=44 \%(42-46 \%, 95 \%$ confidence interval). The shaded area represents the $95 \%$ confidence interval

density. For developing countries with low levels of urbanization, a large portion of the population is rural and resides in single-story buildings that lack adequate protection from earthquake-induced shaking. When a large earthquake event occurs, the collapse of these buildings led to a large number of deaths (Jackson 2006). This is especially true for rural households in semiarid and arid climates (for example, Iran and Pakistan), where the main source of building materials are mud bricks and shelters have heavy clay roofing (Jackson 2006; Spence 2007; Motamedi et al. 2012). This may also explain why the estimated proportion of earthquake fatalities in rural areas to total fatalities were over $80 \%$ from 2003 to 2018; such was the case resulting from the 2005 Kashmir and 2015 Nepal earthquakes (Wyss 2018). In addition, countries with low levels of urbanization typically struggle with poverty and corruption, and the earthquake resistance of buildings is largely overlooked, especially with the expansion of informal settlements (Green 2008; Ambraseys and Bilham 2011; Bilham and Gaur 2013).

With the movement of population from rural areas to urban areas with a high population density (that is, urbanization), the exposure rate to earthquakes changes (Jackson 2006; Doocy et al. 2013b; Bai et al. 2017). Furthermore, most developing countries with earthquakeprone areas lack or have weak enforcement of building codes for earthquakes (Daniell et al. 2014), which affects population vulnerability. Among the 94 countries having earthquake-prone areas over the last 28 years, more than $70 \%$ of total deaths occurred in countries with a vulnerability code of 4 or 5 in the PAGER system and an urbanization ratio between 20 and 60\% (Fig. 5). If an earthquake with a large magnitude strikes a rapidly urbanizing area with a weak building resistance, the potential exists for a large number of fatalities (Daniell et al. 2017). For example, substantially more deaths occurred in urban areas than rural areas from both the 1976 Tangshan Earthquake in China (242 thousand deaths) and the 31thousand deaths of the 2003 Bam Earthquake in Iran (EM-DAT 2018). In other words, among countries with a middle level of urbanization, both the collapse of fragile single-floor rural settlements as well as unreinforced multifloor urban apartments contribute to earthquake fatalities.

A third conceptual urbanization stage occurs when earthquake fatalities substantially decline, likely due to the enactment and strong enforcement of building codes (Crowley and Elliott 2012) and increased economic prosperity that situates more of the population in higher quality structures (Jackson 2006). This is especially true for highly developed countries, such as the United States, New Zealand, and Japan. The data support this transition with only a small portion of total deaths (1.3-1.7\%) in global earthquake-prone areas during 1990-2018 occurring in the United States, New Zealand, and Japan (Fig. 5). Previous studies also supported this finding (Ambraseys and Bilham 2011; He et al. 2018). For example, Spence (2007) found that the annual fatalities caused by earthquakes to the total population in the United States and Japan decreased from 41 and 2670 persons per million to 3.4 and 230 victims, respectively. In contrast, the fatality number in Iran increased from 308 persons per million pre-1960 to 2970 since the 1980s because of the weak enforcement of building codes. Other researchers further support the argument that urbanization provides a reduction in earthquake mortality risk by improving: (1) the technology for sending earthquake alerts (Suárez et al. 2009); (2) knowledge about mitigating seismic risk (Takeuchi and Shaw 2014); and (3) access to shelter during earthquakes (Alçada-Almeida et al. 2009).

\subsection{Implications of Future Urbanization in Global Earthquake-Prone Areas}

Population and urban land area will likely continue to increase in global earthquake-prone areas in the future (Table 3). According to the projections of population and urban land area under the five Shared Socioeconomic Pathways (SSPs) examined by O'Neill et al. (2014, 2017), the population in global earthquake-prone areas will increase by 376.23 (215.05-593.87) million from 2015 to 
Table 3 Estimates of population and urban land in global earthquake-prone areas from 2015 to 2050 under the five Shared Socioeconomic Pathways

\begin{tabular}{|c|c|c|c|}
\hline & 2015-2050 & Proportion* & Rate of change \\
\hline \multicolumn{4}{|l|}{ Population (million) } \\
\hline Global earthquake-prone areas & $\begin{array}{l}376.23 \\
(215.05-593.87)\end{array}$ & & $\begin{array}{l}24.9 \% \\
(14.3-39.4 \%)\end{array}$ \\
\hline $0<U R \leq 20 \%$ & $\begin{array}{l}0 \\
(0)\end{array}$ & $\begin{array}{l}0 \% \\
(0)\end{array}$ & $\begin{array}{l}0 \\
(0)\end{array}$ \\
\hline $20 \%<U R \leq 40 \%$ & $\begin{array}{l}18.79 \\
(9.46-28.91)\end{array}$ & $\begin{array}{l}4.9 \% \\
(4.4-5.0 \%)\end{array}$ & $\begin{array}{l}46.0 \% \\
(23.2-70.8 \%)\end{array}$ \\
\hline $40 \%<U R \leq 60 \%$ & $\begin{array}{l}193.63 \\
(105.30-322.26)\end{array}$ & $\begin{array}{l}51.5 \% \\
(49.0-54.3 \%)\end{array}$ & $\begin{array}{l}36.5 \% \\
(19.9-60.8 \%)\end{array}$ \\
\hline $60 \%<U R \leq 80 \%$ & $\begin{array}{l}88.45 \\
(36.68-147.18)\end{array}$ & $\begin{array}{l}23.5 \% \\
(24.8-17.1 \%)\end{array}$ & $\begin{array}{l}21.1 \% \\
(8.8-35.1 \%)\end{array}$ \\
\hline $80 \%<U R \leq 100 \%$ & $\begin{array}{l}75.36 \\
(55.91-95.52)\end{array}$ & $\begin{array}{l}20.0 \% \\
(16.1-26.0 \%)\end{array}$ & $\begin{array}{l}14.5 \% \\
(10.8-18.4 \%)\end{array}$ \\
\hline \multicolumn{4}{|l|}{ Urban land $\left(\mathrm{km}^{2}\right)$} \\
\hline Global earthquake-prone areas & $\begin{array}{l}60,991 \\
(47761-73522)\end{array}$ & & $\begin{array}{l}65.0 \% \\
(50.9-78.3 \%)\end{array}$ \\
\hline $0<U R \leq 20 \%$ & $\begin{array}{l}0 \\
(0)\end{array}$ & $\begin{array}{l}0 \% \\
(0)\end{array}$ & $\begin{array}{l}0 \\
(0)\end{array}$ \\
\hline $20 \%<U R \leq 40 \%$ & $\begin{array}{l}905 \\
(565-1516)\end{array}$ & $\begin{array}{l}1.5 \% \\
(1.2-2.1 \%)\end{array}$ & $\begin{array}{l}275.0 \% \\
(171.7-460.8 \%)\end{array}$ \\
\hline $40 \%<U R \leq 60 \%$ & $\begin{array}{l}16,875 \\
(13,042-22,428)\end{array}$ & $\begin{array}{l}27.7 \% \\
(27.3-30.5 \%)\end{array}$ & $\begin{array}{l}179.7 \% \\
(138.9-238.8 \%)\end{array}$ \\
\hline $60 \%<U R \leq 80 \%$ & $\begin{array}{l}15,925 \\
(11,766-30,521)\end{array}$ & $\begin{array}{l}26.1 \% \\
(24.6-27.9 \%)\end{array}$ & $\begin{array}{l}83.3 \% \\
(61.5-107.1 \%)\end{array}$ \\
\hline $80 \%<U R \leq 100 \%$ & $\begin{array}{l}27,286 \\
(22,388-30,521)\end{array}$ & $\begin{array}{l}44.7 \% \\
(41.5-46.9 \%)\end{array}$ & $\begin{array}{l}42.0 \% \\
(34.4-78.3 \%)\end{array}$ \\
\hline
\end{tabular}

*The proportion refers to the change of population and urban land in each group of countries to the total change in global earthquake-prone areas. $U R$ stands for the urbanization ratio, percentage or urban population to total population. The values in bracket are the minimum and maximum values among the five Shared Socioeconomic Pathways

2050 , with a rate of growth of $24.9 \%$ (14-39.4\%). Meanwhile, the increase in urban land area in global earthquakeprone areas will likely be $60,991(47,761-73,522) \mathrm{km}^{2}$, with a rate of growth of $65.0 \%$ (50.9-78.3\%). Population density in urban areas in global earthquake-prone areas will decrease along with the increase in urbanization.

More than half of the total increase in population $(51.5 \%)$ in global earthquake-prone areas will occur in nations that will have an urbanization ratio between 40 and 60\% (Table 3). In particular, Pakistan, India, Afghanistan, and Bangladesh will rank in the top four. The total population growth in these four countries' earthquake-prone areas will reach $181.62(92.62-300.05)$ million, accounting for $48.3 \%(43.1-50.5 \%)$ of total population growth in global earthquake-prone areas. This is consistent with previous findings that most of the urban agglomeration growth at risk will be in Asian developing countries (Bilham 1999, 2009).

Our study reveals that these countries are mostly expected to pass the $44 \%$ turning point in the urbanization ratio by 2050 , which implies that adequate strategies to improve building resistance to earthquakes should be adopted more rapidly than has been done in the past. For the next three decades in these countries, a window exists in which to provide a safer living environment for local residents (Ambraseys and Bilham 2011; Uitto and Shaw 2016). Among these developing countries, increased urbanization and population growth is typically accompanied by the expansion of informal settlements and multistory buildings, which are especially vulnerable to catastrophic natural hazards and disasters (Jaiswal et al. 2011a; Henderson et al. 2016). Thus, mitigating the seismic risk of the urban poor and enhancing the seismic resilience 
of high-rise buildings should be prioritized to decrease seismic risk in developing countries.

Approximately $45 \%$ of urban land growth in global earthquake-prone areas will take place in countries with an urbanization ratio above $80 \%$ in 2050 (Table 3). This could be good news for global seismic risk mitigation, as historical urban expansion in the developed countries is characterized by reinforced buildings for earthquake resistance and sprawling development that disperses impact (Spence 2007). Several developed countries have successful historical experiences dealing with seismic risk and mitigating fatalities during large earthquakes (Spence 2007; Crowley and Elliott 2012). If careful and rigorous disaster planning and operationalization of policy to ensure code enforcement for seismic resistance and retrofit of buildings are upheld (Bilham 2009; Samaddar et al. 2017), policy initiative will lead to further success stories. Enhancing the resilience of buildings, infrastructure, and urban systems in rapidly urbanizing cities would increase the capacity to cope with catastrophic earthquakes by medium and small urban centers.

\subsection{Limitations and Future Perspectives}

We analyzed the spatiotemporal dynamics of population and urban land exposed to earthquake hazard globally, and investigated the association between urbanization and earthquake fatalities. The results suggest that as the urbanization ratio increases from low to moderate values, earthquake-induced fatalities also increase. However, as the urbanization ratio increases from moderate to higher levels (that is, 40-60\%), fatalities decreased. Under data limitations for our global analysis, the range of uncertainty is highest at the ends of the urbanization ratio (that is, low and high; Fig. 7). But with inclusion of variation in earthquake fatality estimates the presented evidence supports a Kuznet's curve type of response in fatalities due to an increasing urbanization ratio. While we present an analysis of the relationship between urbanization and earthquake fatalities globally, the limited time span of 25 years and coarse spatial resolution of population and urban land data may not be sufficient to form a definitive conclusion. We hope it will provide a point of departure for further studies that use newly available population and urban land datasets on various scales (Merkens et al. 2016; Boke-Olén et al. 2017; Chen et al. 2020a; Chen et al. 2020b; Chen et al. 2020c).

Furthermore, some factors that can affect earthquake fatalities, such as age and gender distribution were omitted due to a lack of data availability at the global scale. Given the disparate effect of catastrophes on different demographics (Vink and Takeuchi 2013), the geographic heterogeneity of demography could provide additional insight into at-risk populations or guide mitigations efforts targeted at specific demographic segments of the population (Jackson 2006).

Lastly, while it is likely that poor building resistance to earthquakes in developing countries is a dominant driver of the observed inverted U-shaped relationship between urbanization and earthquake fatalities at the global scale, new national or global data on the spatial distribution of informal settlements and poorly constructed buildings are required to understand the contribution of informal settlements relative to other factors impacting earthquake fatalities.

\section{Conclusions}

Over the past 25 years, approximately $67.8 \%$ of population growth and $74.5 \%$ of the total deaths, or 307,918 $(282,938-405,431)$ deaths in global earthquake-prone areas took place in developing countries with an urbanization ratio between 20 and $60 \%$ in 2015 . In contrast, only $30.5 \%$ of urban land expansion in global earthquake-prone areas occurred in these countries. The relation between the urbanization ratio and fatalities exhibited an inverted U-shape, with a turning point at approximately $44 \%$ (42-46\%, 95\% confidence interval), after considering other factors such as hazard, exposure, and vulnerability.

By 2050 , more than $50 \%$ of the total increase in population in global earthquake-prone areas will still take place in developing countries with an urbanization ratio between 40 and $60 \%$ in 2050. Among the 94 countries having earthquake-prone areas, 16 of them will pass the urbanization turning point (44\%) before 2050. Special attention to building resistance to earthquake fatalities should be initiated in developing countries (Haiti, Pakistan, India, Afghanistan, and Bangladesh) in the future to mitigate earthquake risk.

Acknowledgements We express our gratitude to the anonymous reviewers and editors for their insightful and critical comments, which have improved the quality of the manuscript. The research presented was supported by the National Key Research and Development Program of China (Grant Number 2019YFA0607203), the National Natural Science Foundation of China (Grant Number 41971225), and the Tang Zhongying Young Scholar Program (Qingxu Huang is a recipient of the program of Beijing Normal University).

Open Access This article is licensed under a Creative Commons Attribution 4.0 International License, which permits use, sharing, adaptation, distribution and reproduction in any medium or format, as long as you give appropriate credit to the original author(s) and the source, provide a link to the Creative Commons licence, and indicate if changes were made. The images or other third party material in this article are included in the article's Creative Commons licence, unless indicated otherwise in a credit line to the material. If material is not included in the article's Creative Commons licence and your intended 
use is not permitted by statutory regulation or exceeds the permitted use, you will need to obtain permission directly from the copyright holder. To view a copy of this licence, visit http://creativecommons. org/licenses/by/4.0/.

\section{References}

Abramson, D.B., and Y. Qi. 2011. "Urban-rural integration" in the earthquake zone: Sichuan's post-disaster reconstruction and the expansion of the Chengdu Metropole. Pacific Affairs 84(3): 495-523.

Aitsi-Selmi, A., S. Egawa, H. Sasaki, C. Wannous, and V. Murray. 2015. The Sendai framework for disaster risk reduction: Renewing the global commitment to people's resilience, health, and well-being. International Journal of Disaster Risk Science 6(2): 164-176.

Alçada-Almeida, L., L. Tralhao, L. Santos, and J. CoutinhoRodrigues. 2009. A multiobjective approach to locate emergency shelters and identify evacuation routes in urban areas. Geographical Analysis 41(1): 9-29.

Alirol, E., G. Laurent, S. Beat, C. François, and L. Louis. 2011. Urbanisation and infectious diseases in a globalised world. The Lancet Infectious Diseases 11(2): 131-141.

Allen, T.I., K.D. Marano, P.S. Earle, and D.J. Wald. 2009. PAGERCAT: A composite earthquake catalog for calibrating global fatality models. Seismological Research Letters 80(1): 57-62.

Ambraseys, N., and R. Bilham. 2011. Corruption kills. Nature 469(7329): 153-155.

Bai, X., T. McPhearson, H. Cleugh, H. Nagendra, X. Tong, T. Zhu, and Y.G. Zhu. 2017. Linking urbanization and the environment: Conceptual and empirical advances. Annual Review of Environment and Resources 42(1): 215-240.

Bilham, R. 1999. Millions at risk as big cities grow space in earthquake zones. Nature 401(6755): 738-738.

Bilham, R. 2004. Urban earthquake fatalities: A safer world, or worse to come?. Seismological Research Letters 75(6): 706-712.

Bilham, R. 2009. The seismic future of cities. Bulletin of Earthquake Engineering 7(4): 839-887.

Bilham, R. 2014. Aggravated earthquake risk in South Asia: Engineering versus human nature. In Earthquake hazard, risk and disasters, ed. J.F. Shroder, and M. Wyss, 103-141. Boston: Academic Press.

Bilham, R., and V. Gaur. 2013. Buildings as weapons of mass destruction. Science 341(6146): 618-619.

Bloom, D.E., D. Canning, and G. Fink. 2008. Urbanization and the wealth of nations. Science 319(5864): 772-775.

Boke-Olén, N., A. Abdi, O. Hall, and V. Lehsten. 2017. Highresolution African population projections from radiative forcing and socio-economic models, 2000 to 2100 . Scientific Data 4(1): $1-9$.

Chen, G., X. Li, X. Liu, Y. Chen, X. Liang, J. Leng, X. Xu, W. Liao, et al. 2020a. Global projections of future urban land expansion under shared socioeconomic pathways. Nature Communications 11: Article 537.

Chen, Y., F. Guo, J. Wang, W. Cai, C. Wang, and K. Wang. 2020 b. Provincial and gridded population projection for China under shared socioeconomic pathways from 2010 to 2100. Scientific Data 7(1): 1-13.

Chen, Y., X. Li, K. Huang, M. Luo, and M. Gao. 2020c. Highresolution gridded population projections for China under the shared socioeconomic pathways. Earth's Future 8(6): Article e2020EF001491.
Crowley, K., and J.R. Elliott. 2012. Earthquake disasters and resilience in the global North: Lessons from New Zealand and Japan. The Geographical Journal 178(3): 208-215.

Daniell, J.E., B. Khazai, F. Wenzel, and A. Vervaeck. 2011. The CATDAT damaging earthquakes database. Natural Hazards and Earth System Sciences 11(8): 2235-2251.

Daniell, J.E., A.M. Schaefer, and F. Wenzel. 2017. Losses associated with secondary effects in earthquakes. Frontiers in Built Environment 3: Article 30

Daniell, J.E., F. Wenzel, B. Khazai, J.G. Santiago, and A. Schaefer. 2014. A worldwide seismic code index, country-by-country global building practice factor and socioeconomic vulnerability indices for use in earthquake loss estimation. In Proceedings of 2nd European Conference on Earthquake Engineering and Seismology, 25-29 August 2014, Istanbul, Turkey.

de Ruiter, M.C., P.J. Ward, J.E. Daniell, and J.C.J.H. Aerts. 2017. Review article: A comparison of flood and earthquake vulnerability assessment indicators. Natural Hazards and Earth System Sciences 17(7): 1231-1251.

Djordjević, M., A. Radivojević, R. Dragović, and I. Filipović. 2016. Exposure to earthquakes-distribution and change of the world's population with regard to disposition of seismic activities. Journal of the Geographical Institute "Jovan Cvijic" SASA 66(3): 353-370.

Doberstein, B., and H. Stager. 2013. Towards guidelines for postdisaster vulnerability reduction in informal settlements. Disasters 37(1): 28-47.

Doocy, S., M. Cherewick, and T. Kirsch. 2013a. Mortality following the Haitian earthquake of 2010: A stratified cluster survey. Population Health Metrics 11: Article 5.

Doocy, S., A. Daniels, C. Packer, A. Dick, and T.D. Kirsch. 2013. The human impact of earthquakes: A historical review of events 1980-2009 and systematic literature review. PLoS Currents Disasters. https://doi.org/10.1371/currents.dis. 67bd14fe457f1db0b5433a8ee20fb833.

Dou, Y., Q. Huang, C. He, S. Meng, and Q. Zhang. 2018. Rapid population growth throughout Asia's earthquake-prone areas: A multiscale analysis. International Journal of Environmental Research and Public Health 15(9): Article 1893.

EM-DAT. 2018. The Emergency Events Database. Brussels, Belgium: Centre for Research on the Epidemiology of Disasters (CRED). www.emdat.be. Accessed 16 Nov 2021.

England, P., and J. Jackson. 2011. Uncharted seismic risk. Nature Geoscience 4(6): 348-349.

Frolking, S., T. Milliman, K.C. Seto, and M.A. Friedl. 2013. A global fingerprint of macro-scale changes in urban structure from 1999 to 2009. Environmental Research Letters 8(2): Article 024004.

Gerstenberger, M.C., W. Marzocchi, T. Allen, M. Pagani, J. Adams, L. Danciu, E.H. Field, H. Fujiwara, et al. 2020. Probabilistic seismic hazard analysis at regional and national scale: State of the art and future challenges. Reviews of Geophysics 58(2): Article e2019RG000653.

Goldewijk, K.K. 2016. A historical land use data set for the Holocene; HYDE 3.2 (replaced). The Hague: Data Archiving and Networked Services (DANS).

Green, R. 2008. Informal settlements and natural hazard vulnerability in rapid growth cities. In Hazards and the built environment: Attaining built-in resilience, ed. L. Bosher, 218-237. London and New York: Routledge.

Güneralp, B., M. Reba, B.U. Hales, E.A. Wentz, and K.C. Seto. 2020. Trends in urban land expansion, density, and land transitions from 1970 to 2010: A global synthesis. Environmental Research Letters 15(4): Article 044015.

He, C., Q. Huang, Y. Dou, W. Tu, and J. Liu. 2016. The population in China's earthquake-prone areas has increased by over 32 million 
along with rapid urbanization. Environmental Research Letters 11(7): Article 074028.

He, X., J. Wu, C. Wang, and M. Ye. 2018. Historical earthquakes and their socioeconomic consequences in China: 1950-2017. International Journal of Environmental Research and Public Health 15(12): Article 2728.

Henderson, J.V., A.J. Venables, T. Regan, and I. Samsonov. 2016. Building functional cities. Science 352(6288): 946-947.

Holzer, T.L., and J.C. Savage. 2013. Global earthquake fatalities and population. Earthquake Spectra 29(1): 155-175.

Huang, Q., S. Meng, C. He, Y. Dou, and Q. Zhang. 2018. Rapid urban land expansion in earthquake-prone areas of China. International Journal of Disaster Risk Science 10(1): 43-56.

IPCC (Intergovernmental Panel on Climate Change). 2018. Summary for policymakers. In Global warming of $1.5^{\circ} \mathrm{C}$. An IPCC special report on the impacts of global warming of $1.5^{\circ} \mathrm{C}$ above preindustrial levels and related global greenhouse gas emission pathways, in the context of strengthening the global response to the threat of climate change, sustainable development, and efforts to eradicate poverty, ed. V. Masson-Delmotte, P. Zhai, H.-O. Pörtner, D. Roberts, J. Skea, P.R. Shukla, A. Pirani, W. Moufouma-Okia, et al., 3-24. Geneva: World Meteorological Organization.

Ishibe, T., and K. Shimazaki. 2012. Characteristic earthquake model and seismicity around late quaternary active faults in Japan. Bulletin of the Seismological Society of America 102(3): 1041-1058.

Jackson, J. 2006. Fatal attraction: Living with earthquakes, the growth of villages into megacities, and earthquake vulnerability in the modern world. Philosophical Transactions of the Royal Society A: Mathematical, Physical and Engineering Sciences 364(1845): 1911-1925.

Jaiswal, K., and D. Wald. 2010. An empirical model for global earthquake fatality estimation. Earthquake Spectra 26(4): 1017-1037.

Jaiswal, K., W. David, and D. Dina. 2011a. Developing empirical collapse fragility functions for global building types. Earthquake Spectra 27(3): 775-795.

Jaiswal, K.S., D.J. Wald, P.S. Earle, K.A. Porter, and M. Hearne. 2011b. Earthquake casualty models within the USGS Prompt Assessment of Global Earthquakes for Response (PAGER) system. In Human casualties in earthquakes, ed. R. Spence, E. So, and C. Scawthorn, 83-94. Dordrecht: Springer.

Jiang, L., and B.C. O'Neill. 2017. Global urbanization projections for the Shared Socioeconomic Pathways. Global Environmental Change 42: 193-199.

Lankao, R.P., and H. Qin. 2011. Conceptualizing urban vulnerability to global climate and environmental change. Current Opinion on Environmental Sustainability 3(3): 142-149.

Lavell, A., M.D. Oppenheimer, J. Hess, R. Lempert, J. Li, R. MuirWood, and S. Myeong. 2012. Climate change: New dimensions in disaster risk, exposure, vulnerability, and resilience. In Managing the risks of extreme events and disasters to advance climate change adaptation, ed. C.B. Field, V. Barros, T.F. Stocker, D. Qin, D.J. Dokken, K.L. Ebi, M.D. Mastrandrea, K.J. Mach, et al., 25-64. A special report of working groups I and II of the Intergovernmental Panel on Climate Change (IPCC). Cambridge and New York: Cambridge University Press.

Leyk, S., A.E. Gaughan, S.B. Adamo, A. de Sherbinin, D. Balk, S. Freire, A. Rose, and F.R. Stevens et al. 2019. The spatial allocation of population: A review of large-scale gridded population data products and their fitness for use. Earth System Science Data 11(3): 1385-1409.

Li, M., Z. Zou, G. Xu, and P. Shi. 2015. Mapping earthquake risk of the world. In World atlas of natural disaster risk, ed. P. Shi, and
R. Kasperson, 25-39. IHDP/Future Earth-Integrated Risk Governance Project Series. Berlin and Heidelberg: Springer.

Liu, M., and S. Stein. 2016. Mid-continental earthquakes: Spatiotemporal occurrences, causes, and hazards. Earth-Science Reviews 162: 364-386.

Martins, V.N., P. Cabral, and D. Sousa. 2012. Urban modeling for seismic prone areas: The case study of Vila Franca do Campo (Azores Archipelago, Portugal). Natural Hazards and Earth System Sciences 12(9): 2731-2741.

Merkens, J.-L., L. Reimann, J. Hinkel, and A. Vafeidis. 2016. Gridded population projections for the coastal zone under the Shared Socioeconomic Pathways. Global and Planetary Change 145: 57-66.

Motamedi, M.H.K., M. Sagafinia, A. Ebrahimi, E. Shams, and M.K. Motamedi. 2012. Major earthquakes of the past decade (2000-2010): A comparative review of various aspects of management. Trauma Monthly 17(1): 219-229.

Montgomery, M.R. 2008. The urban transformation of the developing world. Science 319(5864): 761-764.

Mulligan, G.F. 2013. Revisiting the urbanization curve. Cities 32: 113-122.

Munich Re. 2009. Globe of Natural Disasters, MRNATHAN DVD. Munich Reinsurance Company.

Nagendra, H., X. Bai, E.S. Brondizio, and S. Lwasa. 2018. The urban south and the predicament of global sustainability. Nature Sustainability 1(7): 341-349.

NGDC/WDS (National Geophysical Data Center/World Data Service). 2018. Significant earthquake database. Boulder, CO: National Geophysical Data Center, NOAA.

Northam, R.M. 1979. Urban geography, 2nd edn. New York: John Wiley \& Sons.

O’Neill, B.C., E. Kriegler, K.L. Ebi, E. Kemp-Benedict, K. Riahi, D.S. Rothman, B.J. van Ruijven, and D.P. van Vuuren et al. 2017. The roads ahead: Narratives for shared socioeconomic pathways describing world futures in the 21st century. Global Environmental Change 42: 169-180.

O’Neill, B.C., E. Kriegler, K. Riahi, K.L. Ebi, S. Hallegatte, T.R. Carter, R. Mathur, and D.P. van Vuuren. 2014. A new scenario framework for climate change research: The concept of shared socioeconomic pathways. Climatic Change 122(3): 387-400.

Oteng-Ababio, M. 2012. Neglected vulnerabilities in a rapidly urbanizing city: Reflections on earthquake risks in Accra. Journal of Housing and the Built Environment 27(2): 187-205.

Pagani, M., J. Garcia-Pelaez, R. Gee, K. Johnson, V. Poggi, R. Styron, G. Weatherill, M. Simionato, et al. 2018. Global Earthquake Model (GEM) seismic hazard map (version 2018.1 - December 2018). https://maps.openquake.org/map/global-seismic-hazardmap/\#3/32.00/-2.00. Accessed 20 Nov 2021

Pagani, M., D. Monelli, G. Weatherill, L. Danciu, H. Crowley, V. Silva, P. Henshaw, and L. Butler et al. 2014. OpenQuake engine: An open hazard (and risk) software for the global earthquake model. Seismological Research Letters 85(3): 692-702.

Panza, G.F., and J. Bela. 2020. NDSHA: A new paradigm for reliable seismic hazard assessment. Engineering Geology 275: 105403.

Peduzzi, P., H. Dao, C. Herold, and F. Mouton. 2009. Assessing global exposure and vulnerability towards natural hazards: The disaster risk index. Natural Hazards and Earth System Sciences 9(4): 1149-1159.

Pesaresi, M., D. Ehrlich, T. Kemper, A. Siragusa, A.J. Florczyk, S. Freire, and C. Corbane. 2017. Atlas of the human planet 2017: Global exposure to natural hazards. Luxembourg: Publications Office of the European Union. https://publications.jrc.ec.europa. eu/repository/handle/JRC106292. Accessed 20 Nov 2021.

Potere, D., and A. Schneider. 2007. A critical look at representations of urban areas in global maps. GeoJournal 69(1-2): 55-80. 
Ravallion, M., and D. van de Walle. 1991. Urban-rural cost-of-living differentials in a developing economy. Journal of Urban Economics 29(1): 113-127.

Riahi, K., D.P. van Vuuren, E. Kriegler, J. Edmonds, B.C. O’Neill, S. Fujimori, N. Bauer, and K. Calvin et al. 2017. The shared socioeconomic pathways and their energy, land use, and greenhouse gas emissions implications: An overview. Global Environmental Change 42: 153-168.

Samaddar, S., N. Okada, J. Choi, and H. Tatano. 2017. What constitutes successful participatory disaster risk management? Insights from post-earthquake reconstruction work in rural Gujarat, India. Natural Hazards 85(1): 111-138.

Sarris, A., C. Loupasakis, P. Soupios, V. Trigkas, and F. Vallianatos. 2010. Earthquake vulnerability and seismic risk assessment of urban areas in high seismic regions: Application to Chania City, Crete Island, Greece. Natural Hazards 54(2): 395-412.

Shucksmith, M., S. Cameron, T. Merridew, and F. Pichler. 2009. Urban-rural differences in quality of life across the European Union. Regional Studies 43(10): 1275-1289.

Spence, R. 2007. Saving lives in earthquakes: Successes and failures in seismic protection since 1960. Bulletin of Earthquake Engineering 5(2): 139-251.

Suárez, G., D. Novelo, and E. Mansilla. 2009. Performance evaluation of the seismic alert system (SAS) in Mexico City: A seismological and a social perspective. Seismological Research Letters 80(5): 707-716.

Takeuchi, Y., and R. Shaw. 2014. New insights of education sector from East Japan earthquake and tsunami. In Disaster recovery, ed. R. Shaw, 147-164. Tokyo: Springer.

Uitto, J.I., and R. Shaw. 2016. Sustainable development and disaster risk reduction: Introduction. In Sustainable development and disaster risk reduction, ed. J.I. Uitto, and R. Shaw, 1-12. Tokyo: Springer.

UN (United Nations). 2015. Sendai framework for disaster risk reduction 2015-2030. New York: United Nations.

UN (United Nations). 2019. World urbanization prospects: The 2018 revision. New York: United Nations Publications.
UNDP (United Nations Development Programme). 2018. 2018 statistical update: Human development indices and indicators. New York: UNDP.

UNHCR (United Nations High Commissioner for Refugees). 2014. Global strategy for settlement and shelter. http://www.unhcr.org/ 530f13aa9.pdf. Accessed 20 Apr 2018.

UNISDR (United Nations International Strategy for Disaster Reduction). 2017. GAR atlas: Unveiling global disaster risk. Geneva: UNISDR.

Utsu, T. 2004. Catalog of damaging earthquakes in the world (through 2002). Tokyo: Tokyo University and International Institute of Seismology and Earthquake Engineering. https://iisee.kenken. go.jp/utsu/index_eng.html. Accessed 21 Nov 2021.

van Vuuren, D.P., E. Kriegler, B.C. O’Neill, K.L. Ebi, K. Riahi, T.R. Carter, J. Edmonds, and S. Hallegatte et al. 2014. A new scenario framework for climate change research: Scenario matrix architecture. Climatic Change 122(3): 373-386.

Vink, K., and K. Takeuchi. 2013. International comparison of measures taken for vulnerable people in disaster risk management laws. International Journal of Disaster Risk Reduction 4: 63-70.

Ward, P.J., V. Blauhut, N. Bloemendaal, J.E. Daniell, M.C. de Ruiter, M.J. Duncan, R. Emberson, and S.F. Jenkins et al. 2020. Review article: Natural hazard risk assessments at the global scale. Natural Hazards and Earth System Sciences 20(4): 1069-1096.

Wyss, M. 2015. Testing the basic assumption for probabilistic seismic-hazard assessment: 11 failures. Seismological Research Letters 86(5): 1405-1411.

Wyss, M. 2018. Rural populations suffer most in great earthquakes. Seismological Research Letters 89(6): 1991-1997.

York, R., E.A. Rosa, and T. Dietz. 2003. STIRPAT, IPAT and ImPACT: Analytic tools for unpacking the driving forces of environmental impacts. Ecological Economics 46(3): 351-365. 